\title{
Intensive care unit organisation and nurse outcomes: A cross-sectional study of traditional and "hot-floor" structures
}

\author{
Brett Abbenbroek, Christine Duffield, Doug Elliott \\ Centre for Health Servcies Management, Faculty of Health, University of Technology Sydney, Australia
}

Received: May 2, 2017

Accepted: May 24, 2017

Online Published: June 1, 2017

DOI: $10.5430 /$ jha.v6n3p67

URL: https://doi.org/10.5430/jha.v6n3p67

\begin{abstract}
Aim: To explore the relationship between the practice environment and nurse outcomes in two Intensive Care Unit (ICU) models. Background: Internationally the demand for intensive care is increasing. A large capacity multi-specialty integrated critical care service, the "hot-floor", is emerging as the preferred organisational model. Benefits include resource consolidation and improved utilisation, operational synergies, operational flexibility and demand management. A large clinical workforce with commensurate frontline management, education and support positions are required. The association between these factors, within the ICU hot-floor work environment, and nurse outcomes is not known.

Methods: Registered nurses (RNs) working in two ICUs, one a hot-floor model and one traditional ICU, completed a structured questionnaire. Nurse perceptions of work-life and organisational factors, and dimensions of burnout were examined using the Practice Environment Scale-Nursing Work Index (PES-NWI) and Maslach's Burnout Inventory (MBI).

Results: Units matched on service level characteristics, training accreditation, patient casemix, operational and clinical care processes. Nurses in had similar demographic characteristics, professional attributes and experience. Workforce structures were also similar though the hot-floor had relatively less dedicated resources for frontline nurse management and clinical education positions. Hot-floor nurses worked more paid overtime and were redeployed less frequently to external wards. Nurse manager leadership and support was less effective, and nurses expressed lower personal accomplishment.

Conclusions: Improved demand management achieved through greater operational flexibility is a key driver for the hot-floor model. Planning for enhanced organisational effectiveness requires corresponding improvements in the work environment to optimise nurse retention to ensure organisational sustainability.
\end{abstract}

Key Words: Burnout, Critical care, Job satisfaction, Nurse, Organisation, Outcome

\section{INTRODUCTION}

Intensive Care Units (ICUs) support critically ill patients that require complex clinical management, sophisticated technologies and high resource inputs. Internationally, the demand for intensive care is growing due to aging populations, higher inpatient acuity with multiple co-morbidities and ad- vanced medical technologies. ${ }^{[1,2]}$

Health services planning that increases bed capacity alone is not sustainable in terms of both fiscal and human resources. ${ }^{[3,4]}$ Effective demand management strategies can improve the flexibility and utilisation of available bed capacity while optimising patient and staff outcomes. ${ }^{[5]}$ Regionalisa-

*Correspondence: Brett Abbenbroek; Email: Brett.J.Abbenbroek@student.uts.edu.au; Address: Centre for Health Services Management, Faculty of Health, University of Technology, Sydney, 15 Broadway Ultimo, NSW 2007, Australia. 
tion or consolidation of ICU services across clinical networks and within individual hospitals into a single integrated service is one key strategy resulting new organisational models for service delivery. ${ }^{[2,6,7]}$

A large-capacity multi-specialty integrated ICU service model, referred to as an ICU "hot-floor" (see Figure 1), is emerging as a preferred organisational approach in tertiary referral hospitals where traditionally sub-specialty ICUs typically operated in isolation. ${ }^{[8-10]}$ Multiple pods (or units) of ICU and high dependency unit (HDU), or "step down", beds are physically collocated and managed as a single integrated service. Critical care sub-specialties include neurosciences, cardiothoracic surgery, trauma and general medicine and surgery. ${ }^{[11]}$ Benefits include consolidation of resources and expertise, improved flexible bed management, enhanced operational synergies and increased standardisation of processes and clinical practice. ${ }^{[12-14]}$

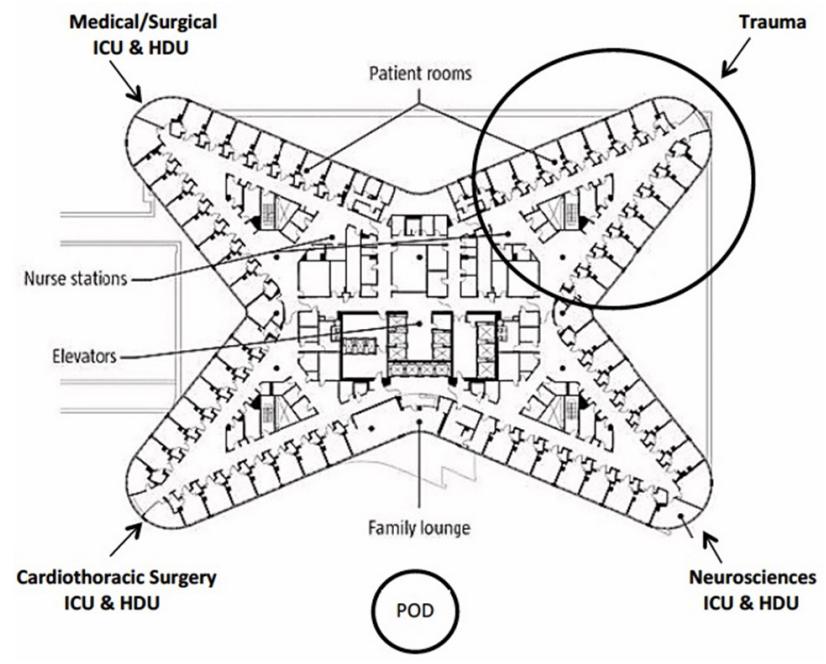

Figure 1. Conceptual model of an integrated hot-floor intensive care service

Capacity of the ICU hot-floor model ranges from 50 to 70 beds in contrast to a conventional ICU that consists of a single pod of between eight to 16 beds. ${ }^{[15,16]}$ Both are managed as closed ICU models in which the ICU team manages patient triage and clinical care, with specialty medical teams consulted as required. Structural requirements and operational processes for effective service management have been specified by professional associations and accrediting agencies. ${ }^{[16-18]}$ As requirements have been developed based on the conventional ICU model the impact on the hot-floor work environment, defined as the organisational characteristics of the workplace that either facilitate or constrain professional nursing practice, is not known. ${ }^{[19]}$

Transition to the hot-floor model requires structural changes to nursing management and education models, supervision and support, staff numbers, resourcing, rostering and staffing. ${ }^{[20-22]}$ Key factors to be considered in determining appropriate models and resourcing include the enhanced hotfloor bed flexibility enabling higher patient volumes per bed and high unit occupancy, and the large clinical workforce. Maintaining appropriate staffing and skill-mix on a 24-hour basis, while optimising nurse outcomes, is a major challenge internationally in the ICU. ${ }^{[23-25]}$ Modified structural factors may exacerbate management challenges, degrade the work environment and increase nurse dissatisfaction, burnout and turnover ${ }^{[26-28]}$ Organisational, emotional and professional factors have long been recognised as contributing factors to burnout in ICU and are increasingly being acknowledged by critical care societies internationally. ${ }^{[29,30]}$

Nurse outcomes such as satisfaction, retention and burnout have been investigated extensively in acute care environments. ${ }^{[31-33]}$ Intensive care nurse outcomes are not so well understood, therefore unsustainable organisational models may be adopted that ultimately impact patient care. In this study, we examined the association between nurse outcomes and organisational factors in the ICU hot-floor work environment. Nurse outcomes are compared to those in a conventional ICU in Australia. As the large integrated closed ICU service model becomes more prevalent internationally due to the regionalisation of critical care services, understanding any impact on nurse outcomes is essential for organisational sustainability in the long-term. ${ }^{[1,30,34]}$

\section{Methods}

\subsection{Study design, setting and sampling}

A prospective cross sectional study was conducted in the ICUs of two separate 650-700 bed university teaching hospitals from April - June 2014. Purposive sampling determined selection of the study settings based on national and international minimum standards for intensive care. ${ }^{[15-17]}$ Specifically service level characteristics, training accreditation, patient casemix, operational management, care processes and the clinical workforce were closely matched and complied with minimum ICU standards. ${ }^{[15,18]}$

The ICU organisational model was the key difference between the two units. At the time of the study, $8.0 \%$ of adult tertiary ICUs in Australia reflected an ICU hot-floor structure. ${ }^{[35]}$ The study ICU hot-floor consisted of 54 beds divided into four sub-specialty pods, including a 17 bed general ICU. The conventional ICU was a stand-alone unit of 15 general ICU beds. All registered nurses (RNs) permanently rostered/scheduled in each general ICU were invited to participate. Inclusion criteria were RNs providing direct patient care in full time or part time employment, all levels of clinical 
experience and either with or without a critical care specialist qualification. The estimated sample size of 130 nurses, 65 from each ICU, was similar to previous studies. ${ }^{[23,36,37]}$ This sample size was calculated to achieve $80 \%$ power to detect a statistical difference $(\alpha=0.05)$, reduce the probability of Type I and II errors, and was appropriate for the analysis of outcome measures aggregated at the unit level. ${ }^{[38]}$

\subsection{Outcomes, instrumentation and ethical considera- tions}

The survey instrument consisted of four sections and a total of 80 items with tick box answers. De-identified nurse demographic and professional characteristics, work-life factors and perceptions were collected. Organisationally mediated outcomes were measured using the validated Practice Environment Scale-Nursing Work Index (PES-NWI) and Maslach's Burnout Inventory (MBI) Human Services Survey. ${ }^{[19,39,40]}$ This study was the first use of this instrument in the Australian intensive care nurse population.

The PES-NWI consists of five subscales measuring nurse participation in hospital affairs; nursing foundations for quality of care; nurse manager ability, leadership, and support of nurses; staffing and resource adequacy; and collegial nursephysician relationships. ${ }^{[19]}$ A four-point scale (strongly disagree, disagree, agree and strongly agree) is used to rate the extent to which the items are present in the participant's workplace. Mean scores above 2.5 indicate agreement that the item is present and scores below 2.5 indicate disagreement. ${ }^{[19]}$

The MBI evaluates the level of nurse burnout with a focus on interpersonal and psychosocial aspects, and greater emphasis on individual perceptions and emotions. ${ }^{[39]}$ Three subscales measure depersonalisation, emotional exhaustion and personal accomplishment using a seven-point response scale ranging from "never having those feelings" to "having those feelings every day" to measure responses. Scoring and interpretation of results is done in comparison to normative data and between nurse samples.

Survey structure, design and formatting were based on a previous large Australian nurse outcome study. ${ }^{[41]}$ The tool was piloted using purposive sampling of 14 clinical RNs from a range of similar ICUs that were representative of the study population but external to the study sample. A pilot response rate of $93 \%$, constituting approximately $10 \%$ of the main study sample size, provided adequate representation. ${ }^{[42]}$ Respondents considered the completion time appropriate ( mean $=11 \mathrm{~min}$; range $=7-15 \mathrm{~min}$ ). Minor grammatical modifications were made to improve clarity but no modifications were made to the PES-NWI or MBI instruments.
Explanatory notes on specific terms were added to the questionnaire and reviewed at staff information sessions. Interrater reliability across respondents was high with overall agreement on the appropriateness of the structure, content, ease of completion and time taken.

Ethics approvals were obtained from the Human Research Ethics Committee of the sites and the University. Permissions were also obtained for use and reproduction of the PES-NWI and MBI survey instruments. Survey completion was deemed as consent to participate.

\subsection{Data collection and analysis}

Information sessions were conducted at each site where the study rationale, objectives and questionnaire were introduced, and staff had the opportunity to ask questions or seek clarification. Hard copy questionnaires completed during the session were returned to the collection point in a coded sealed envelope. Staff email distribution lists were used to circulate an electronic version of the participant information sheet and Survey Monkey link (Survey Monkey Inc., Palo Alto, California, USA, www.surveymonkey.com). The online survey required completion of all items before progressing or exiting the survey. Throughout the study a weekly group email to nursing staff from the Nurse Manager provided a reminder about the study and to return completed surveys. Each response was registered against a confidential list held by an independent observer to mitigate the risk of duplicate responses.

Survey responses were transcribed into an Excel data file and assessed for data quality and integrity. ${ }^{[43]}$ Four surveys were incomplete and not included. The data file was then exported into SPSS (version 22) (SPPS IBM, New York, USA) for statistical analysis. Data analysis initially described the characteristics of the study settings and nurse workforce. Statistical comparisons of nurse demographic characteristics, work-life factors and perceptions were performed using Pearson's Chi Square analysis. Mean subscale scores ensured equal weight was given to each for PES-NWI and MBI subscale to avoid differential weighting for subscales with more items. $^{[44]}$

Both PES-NWI and MBI demonstrated good internal consistency and reliability in the current nurse sample with Cronbach's alpha scores of 0.92 and 0.76 respectively. Principal component analysis indicated a five-factor model for the PESNWI and three-factor model for MBI. ${ }^{[4]}$ Confirmatory factor analysis confirmed the presence of five and three components respectively with Varimax rotation resulting in strong factor loading coefficients exceeding 0.3 . Total variance explained by PES-NWI was $53.7 \%$ and $50.1 \%$ for MBI, consistent with 
earlier studies in similar nurse populations. ${ }^{[45,46]}$ Goodness of fit indices also confirmed five-factor and three-factor models. Strong psychometric properties confirmed applicability to the Australian intensive care nurse population and comparable to similar studies undertaken in a range of healthcare settings internationally. ${ }^{[47-49]}$

Inspection of subscale histograms, normal Q-Q plots and $5 \%$ trimmed means, and tests for skewness and kurtosis confirmed the data had an approximately normal distribution. Multivariate normality was confirmed (PES-NWI = 15.10 [5] and MBI [3] $=10.40 ; p<.001)$ and (PES-NWI = 14.51 [5] and $\mathrm{MBI}[3]=8.87 ; p<.001)$ for the hot-floor and conventional ICU scores, respectively. Chi-square tests, Spearman's correlations, independent $T$-test and multivariate analysis (MANOVA) were conducted. Significant composite score differences were examined by two-way ANOVA, and where appropriate Tukey's post-hoc tests, to examine relationships among nurse characteristics, the work environment and nurse outcomes, and the main affect of ICU origin. ${ }^{[50]}$ Significance was set at $\alpha=0.05$.

\section{RESUlts}

Survey responses were $82(73 \%)$ for the hot-floor and 63 (75\%) for the conventional ICU. Gender, age range and qualification levels were matched. Overall, $78.6 \%$ of the sample was female. The proportion of males in both units $(24.4 \%$ hot-floor vs. $17.5 \%$ conventional ICU) was higher than the national average of $12 \%$ reflecting the preference of males to work in critical care specialties in Australia. ${ }^{[51]}$ Workforce structures and clinical staffing were mostly equivalent across the two units. Notably, the hot-floor had a consistently lower proportion of front-line managers $(11.0 \%$ vs. $16.0 \%)$, educator $(1.25 \%$ vs. $3.70 \%)$, dedicated pharmacist (0.35 vs. 1.0 FTE) and ancillary support positions (1.35 vs. 3.0 FTE) than the conventional ICU.

Nurse work-life factors were matched on clinical and specialist intensive care experience, and the proportion of staff working full time. More Clinical Nurse Specialists (4 years experience plus specialist qualification) worked in the conventional ICU $(23.4 \%$ vs. $15.9 \% ; p=.02)$ but this was offset by there being no difference in years of clinical experience. More conventional ICU nurses were redeployed out of the unit on a shift-by-shift basis $(14.3 \%$ vs. $6.1 \% ; p=.00)$, with ICU origin having a moderately strong influence $(r=0.43) .{ }^{[52]}$ More hot-floor nurses worked 12 -hour shifts $(57 \%$. vs. $32 \% ; p=.00)$ and paid overtime $(28 \%$. vs. $6 \% ; p=.00)$, with ICU origin having a moderate effect $(r=-0.36)$.

Perceptions of local management factors, social cohesion and job satisfaction did not differ significantly between the nurse groups. Of note, nurses in the hot-floor model reported consistently lower ratings for roster flexibility, clinical supervision and access to a clinical educator, while being required to mentor colleagues more often (though not statistically significant). Causation could not therefore be inferred but these findings contribute to interpretation of PES-NWI and MBI results (see Table 1).

Overall, PES-NWI subscale scores indicated a positive work environment in both units. Notably, hot-floor nurses scored lower across the majority of subscales including nurse participation in hospital affairs, nursing foundations for quality of care, nurse manager ability, leadership and support, and staffing and resource adequacy, though not statistically significant. Positive correlation coefficients indicated moderate to strong relationships between all subscales in both ICUs (Hot-floor $r=0.403$ to 0.701 vs. Conventional $r=0.384$ to $0.747 ; p<.05)$.

Hot-floor nurses scored nurse manager ability, leadership and support lower (mean difference $=-0.27,95 \% \mathrm{CI}-0.45$ to -0.094; $p=.003$ ). As such nurse manager ability, leadership and support of nurses accounted for $60 \%$ of variance in the practice environment in both units confirming the crucial role front line nurse managers have on nurse outcomes.

Table 1. PES-NWI subscale scores

\begin{tabular}{llllll}
\hline & Unit & Mean $($ SD) & Min & Max & 95\% CI \\
\hline \multirow{2}{*}{ Nurse participation in hospital affairs } & Hot-floor & $2.8(0.47)$ & 1.7 & 4.0 & $2.7-2.9$ \\
& Conventional & $2.9(0.53)$ & 2.7 & 3.9 & $2.7-3.0$ \\
\multirow{2}{*}{ Nursing foundations for quality of care } & Hot-floor & $2.9(0.44)$ & 1.9 & 4.0 & $2.9-3.0$ \\
& Conventional & $3.1(0.41)$ & 2.1 & 3.9 & $3.0-3.2$ \\
\multirow{2}{*}{ Nurse Manager ability, leadership and support } & Hot-floor & $2.8(0.55)$ & 1.4 & 4.0 & $2.7-3.0$ \\
& Conventional & $3.1(0.50)$ & 1.6 & 4.0 & $3.0-3.2$ \\
Staffing and resource adequacy & Hot-floor & $2.8(0.53)$ & 1.5 & 4.0 & $2.7-3.0$ \\
& Conventional & $3.0(0.57)$ & 1.8 & 4.0 & $2.8-3.1$ \\
Collegial Nurse-Physician Relations & Hot-floor & $3.1(0.52)$ & 1.7 & 4.0 & $3.0-3.2$ \\
& Conventional & $3.1(0.44)$ & 1.7 & 4.0 & $3.0-3.2$ \\
\hline
\end{tabular}


Composite PES-NWI scores had a positive association with nurses holding a non-nursing qualification $(p=.04)$. Hotfloor nurses with a non-nursing masters qualification scored the nurse-doctor collegiality subscale higher $(\bar{x}=3.13 \mathrm{vs}$. $2.80 ; p=.06)$. Conversely, nurse perceived quality of care scores had a negative association with the composite PESNWI score $(p=.03)$, in particular with the nurse participation in hospital affairs subscale $(p=.01)$. Conventional ICU nurses who believed that quality of care had deterio- rated reported a lower level of participation in hospital affairs ( $\bar{x}=1.87$ vs. $2.56 ; p=.06$ ). No post-hoc analysis of either subscale was performed due to the non-significant result.

Mean MBI subscale scores for both units were generally equivalent to normative population scores (see Table 2). Comparing scores between units found that hot-floor respondents reported relatively higher depersonalisation and emotional exhaustion, and lower personal accomplishment scores than conventional ICU nurses.

Table 2. MBI subscale scores

\begin{tabular}{llllll}
\hline & Unit & Mean $^{*}(\boldsymbol{S D})$ & Min & Max & 95\% CI \\
\hline \multirow{2}{*}{ Depersonalisation } & Hot-floor & $7.45(4.71)$ & 0.0 & 19.0 & $6.4-8.5$ \\
& Conventional & $6.06(4.73)$ & 0.0 & 17.0 & $4.9-7.3$ \\
\multirow{2}{*}{ Emotional Exhaustion } & Hot-floor & $22.28(4.71)$ & 2.0 & 52.0 & $19.8-24.8$ \\
& Conventional & $19.14(10.1)$ & 0.0 & 45.0 & $16.6-21.7$ \\
\multirow{2}{*}{ Personal Accomplishment } & Hot-floor & $34.55(6.40)$ & 21.0 & 46.0 & $33.1-36.0$ \\
& Conventional & $36.14(6.38)$ & 18.0 & 47.0 & $34.5-37.8$ \\
\hline
\end{tabular}

Note. ${ }^{*}$ Normative population scores Mean $(S D): \mathrm{DP}=7.12(5.22), \mathrm{EE}=22.19(9.53)$ and $\mathrm{PA}=36.53(7.34)$

A moderately strong positive correlation was evident between MBI depersonalisation and emotional exhaustion subscales in both ICUs (Hot-floor $r=0.438 ; p=.000$ and Conventional $r=0.552 ; p=.000)$. Conversely, personal accomplishment had a significant negative correlation with depersonalisation in both ICU's (Hot-floor $r=-0.378 ; p=.000$ and Conventional $r=-0.258 ; p=.041)$. The MBI composite score was significantly influenced by two factors. Intention to resign within 12 months $(p=.05)$ was positively associated with higher scores for depersonalisation reported by hot-floor respondents ( $\bar{x}=1.86$ vs. $1.39 ; p=.02)$. Due to this variable having only two levels, "Yes" or "No", it was not suitable for post-hoc analysis. Lastly, a lower level of supervision was negatively associated MBI composite scores $(p=.01)$. Specifically, hot-floor respondents reported a lower level personal accomplishment ( $\bar{x}=4.32$ vs. $4.52 ; p=.02)$. Post hoc tests confirmed that where only a fair level of supervision occurred nurses reported lower personal accomplishment $(\bar{x}=4.0$ vs. $4.8 ; p=.01)$, with ICU origin having a small affect $\left(\eta^{2}=0.06\right)$.

\section{Discussion}

This study provides new evidence about the work environment of nurses working in ICU, particularly an ICU hot-floor organisational model. Working in this model demonstrated both positive and negative impacts on nurse outcomes. Areas of potential risk were also identified which if not proactively managed, could further impact on future nurse outcomes, result in a poorer work environment and undermine the longterm sustainability of the ICU hot-floor model. ${ }^{[26,53]}$

Published by Sciedu Press
The primary study finding was that participants from the hot-floor considered nursing leadership weaker and less effective. As front line nursing management positions were shared across multiple pods of beds in this model, visibility and interaction between bedside nurses and clinical nursing managers may be diminished. In the acute care setting key leadership characteristics including visibility, accessibility, consultation, recognition and support have been associated with a positive practice environment and improved nurse outcomes. ${ }^{[54-56]}$ Effective nursing leadership is a key determinant of the work environment for ICU nurses. ${ }^{[26]} \mathrm{A}$ number of secondary study findings related to the hot-floor work environment implicate the effectiveness of nursing leadership in this clinical setting.

Increasingly the link between effective leadership and reduced burnout is being identified in critical care areas. ${ }^{[23,30]}$ Frontline clinical nurse leaders provide supervisor support that acts as a buffer for burnout. ${ }^{[57]}$ Maintaining appropriate leadership resourcing is required to establish and maintain a healthy work environment, optimise nurse outcomes, retain staff and contribute to positive patient outcomes. ${ }^{[56,58]}$ In critical care settings, work complexity at the point of care places greater reliance on bedside nurses to provide mentorship and clinical support to junior colleagues. ${ }^{[22]}$ Front line management, education and clinical support positions must therefore be incrementally increased and aligned to the size of the nursing workforce by modeling the ratio of these resources per each pod of ten to twelve beds. ${ }^{[15]}$ Ensuring visibility, access and interaction with front-line leaders also 
positively affects the level of personal accomplishment and is a key determinant of nurses' intention to leave. ${ }^{[59]}$

Strong clinical leadership provided by nurse managers enables effective clinical supervision, an influential determinant of personal accomplishment. ${ }^{[6]}$ Perceived clinical competency is linked to nurse burnout and may be compounded in ICU by the need to provide complex care to critically ill patients with little supervision. ${ }^{[61]}$ In the hot-floor, less managerial and educational supervision led to senior bedside nurses providing more frequent mentorship (6\%) and clinical advice $(5 \%)$ to nurse colleagues while being responsible for clinical management of their own allocated patient. This is an accepted professional practice in ICU, but if expected continually then the risk of workload fatigue may be exacerbated. ${ }^{[62]}$ This reflected findings in an earlier published study that reduced access to formal education and support structures, by junior nurses and students, diminished personal accomplishment. ${ }^{[63]}$ Furthermore, sufficient nursing front line management and education positions in ICU for clinical training, professional development and effective leadership are recognised as key factors for a positive work environment. ${ }^{[56,64,65]}$

Overall, nurse perceptions of the work environment were statistically equivalent in both units. Of note however, and while not statistically significant in this sample, hot-floor respondents consistently rated multiple factors lower including roster flexibility, clinical supervision and support, quality of care, occupational health and safety, and job satisfaction. These findings may therefore suggest potential workforce risks that if not preemptively mitigated could negatively impact on the work environment and nurse outcomes. Additionally for the hot-floor, approximately $13 \%$ more nurses intended to resign within 12-months and this was associated with a higher level of reported depersonalisation potentially due to the larger clinical workforce reducing the sense of cohesion. ${ }^{[22,66]}$ Disconnected, or isolated, nurses experience poor collegial communication and increased emotional fatigue that manifests as an unfeeling, impersonal or callous response toward patients, family and colleagues. ${ }^{[23,67,68]} \mathrm{Up}$ to $48 \%$ of critical care nurses have been found to experience depersonalisation, the subsequent professional and social isolation of which may hinder participation, undermine teamwork and compound burnout. ${ }^{[69-71]}$ The presence of a nurse manager who is visible and communicates effectively, strengthens the organisational structure and protects the work environment reducing the risks associated with burnout. ${ }^{[27,72]}$

A potentially positive influence of the hot-floor model was in relation to nurses being less likely to be redeployed to external wards on a short-term shift-by-shift basis than those in the conventional ICU. Intensive care nurses possess a broad range of skills applicable to complex patients in a majority of clinical specialties, and as such are highly mobile across the hospital. ${ }^{[73]}$ Redeployment to an unfamiliar clinical setting where immediate care is required by multiple unknown patients creates heightened anxiety. ${ }^{[73]}$ Large integrated ICU services provide the opportunity to move staff internally between unit pods on a shift-by-shift basis to better match skill-mix with patient acuity in response to fluctuations in demand. ${ }^{[74]}$ The conventional ICU is typically staffed with one nurse to one patient in Australia. In contrast the hot-floor accommodates patients with a broader range of clinical dependencies enabling variable staff ratios. As demand and acuity fluctuate the nursing workforce can more readily mobilized internally across pod within the ICU hotfloor service reducing external redeployment. Appropriate staffing and skill-mix in ICU can be better achieved and are key determinants of a positive work environment. ${ }^{[75]}$

The hot-floor model enabled $25 \%$ more nurses to work 12 hour shifts, reflecting the trend in nursing to condense work hours into fewer shifts and increasing time off work. ${ }^{[76]} \mathrm{Ev}$ idence suggests improved job satisfaction and nurse retention. ${ }^{[5]}$ However, more recent studies have found reduced roster flexibility, increased fatigue and burnout. ${ }^{[77-79]}$ Risks to nurse welfare due to longer shifts may also be compounded by increased paid overtime which was worked $22 \%$ more hotfloor nurses. ${ }^{[76]}$ Furthermore, hot-floor operational flexibility increases patient volume per bed and subsequent workload, which when combined with a technically complex and emotionally demanding work environment, may increase nurse fatigue. ${ }^{\left[{ }^{80]}\right.}$ Longer shifts and increased overtime compound the risk of fatigue in the hot-floor, a contributing factor to adverse events occurring to nurses and patients. ${ }^{[81-83]}$

Of note, nurses reporting lower quality of care in the conventional ICU also reported low participation in hospital affairs, though statistically non-significant. The conventional ICU is a stand-alone unit, which may limit opportunities to participate more broadly in hospital affairs. In contrast the hot-floor may provide a greater range of opportunities beyond the unit level, across the broader integrated service level, to participate in quality management, educational and operational management activities. The subsequent professional advancement and participation in decision making is empowering with nurses perceiving their role as more meaningful in determining the quality of care provided. ${ }^{[24,37,84,85]}$

Both units were found to have a positive practice environment and a comparable level of burnout to normative population scores across a range of healthcare settings. ${ }^{[86,87]}$ Consistent with the results for nurse work life perceptions, ICU hot-floor 
nurses rated the practice work environment more negatively across multiple organisational factors. Increased predisposition to burnout was reflected by higher depersonalisation and emotional exhaustion accompanied by lower personal accomplishment. ${ }^{[88,89]}$ Determinants of the practice environment such as leadership, professional practice, autonomy, resourcing and active participation in hospital affairs influence nurse job satisfaction, retention and turnover. ${ }^{[90]}$ Organisational factors also impact the psychological wellbeing of nurses in ICU. ${ }^{[21,91]}$ Burnout resulting from depersonalisation, emotional exhaustion and low personal accomplishment exacerbate this relationship in the work environment and if not proactively managed may result in the ICU hot-floor organisational model, from a nurse workforce perspective, not being sustainable in the long term. ${ }^{[26,30]}$

\subsection{Methodological strengths and limitations}

The study strengths included the sampling approach and use of established measuring instruments. Purposive sampling targeted clinical bedside nurses in ICU and the high homogeneity between the samples reduced potential confounders. The outcome measures used have strong psychometric properties and this was confirmed in this study.

Some limitations were also noted. The cross sectional study design did not permit causal inferences to be made about the relationships found or provide the ability to control for confounders in the study population. The calculated sample size may have increased the risk of bias, underpowered the analysis and potentially introduced Type I error, therefore larger multi-centre research studies are recommended. ${ }^{[92,93]}$

\subsection{Implications for policy, practice and management} Transition to the ICU hot-floor organisational model requires detailed workforce planning on front line management, ed- ucation and clinical support models to ensure resourcing of these positions is appropriate to the size of the clinical workforce. Additional factors, not only workforce size, need specific consideration for proactive prevention strategies including minimizing nurse redeployment and increased participation, both positive attributes found in the ICU hot-floor.

While generalisability of these results to all organisational types of adult ICUs is limited, this is the first study to compare two closed ICU organisational models. The findings therefore provide a solid foundation for future large multicentre studies, such as longitudinal and intervention evaluation research, to confirm and extend the study findings. Targeted interventions require identification of evidence based causal factors through interventional research on specific work environment factors. Acknowledging different cultural, socioeconomic and political contexts of healthcare systems internationally it is recommended that the study findings be replicated in other countries.

\section{Conclunsions}

Improved demand management achieved through greater operational flexibility is a key driver for the adoption of the hot-floor model. Any gains made in organisational effectiveness need to be balanced with corresponding improvements in the work environment to optimise nurse retention and reduce turnover. Adequately resourced front line nursing management and education roles, relative to the large nurse workforce, are required to proactively and effectively mitigate factors that contribute to dissatisfaction and burnout to support organisational sustainability of the hot-floor model.

\section{CONFLicts OF INTEREST Disclosure}

The authors declare they have no conflict of interest.

\section{REFERENCES}

[1] Vincent J. Evidence supports the superiority of closed ICUs for patients and families: Yes. Intensive Care Medicine. 2016; 1-2. https://doi.org/10.1007/s00134-016-4466-5

[2] Wallace DJ, Seymour CW, Kahn JM. Hospital-Level Changes in Adult ICU Bed Supply in the United States. Critical Care Medicine. 2017; 45(1): e67-e76. https://doi.org/10.1097/CCM. 000000 0000002051

[3] Rhodes A, Moreno R, Chiche J. ICU structures and organization: putting together all the pieces of a very complex puzzle. Intensive Care Medicine. 2011; 37(10): 1569. PMid: 21918846. https://doi.org/10.1007/s00134-011-2332-z

[4] Guidet B, van der Voort PHJ, Csomos A. Intensive care in 2050: healthcare expenditure. Intensive Care Medicine. 2017; 43(1): 1-3. https://doi.org/10.1007/s00134-017-4679-2

Published by Sciedu Press
[5] Stone P, Larson E, Mooney-Kane C, et al. Organizational climate and intensive care unit nurses' intention to leave. Critical Care Medicine. 2006; 34(7): 1907-12. PMid: 16625126. https://doi.org/10.1 097/01.CCM.0000218411.53557.29

[6] Meadows C, Rattenberry W, Waldmann C. Centralisation of specialist critical care services. Journal of the Intensive Care Society. 2011; 12(2): 87-9. https://doi.org/10.1177/175114371101 200202

[7] Nguyen Y, Kahn J, Angus D. Reorganizing Adult Critical Care Delivery: The Role of Regionalization, Telemedicine, and Community Outreach. Am J Respir Crit Care Med. 2010; 181(11): 1164-9. https://doi.org/10.1164/rccm.200909-1441CP

[8] Vincent J. Critical care - where have we been and where are we going? Critical Care. 2013;17(Suppl 1: S2): 1-6.

[9] Kahn J, Linde-Zwirble W, Wunsch H, et al. Potential Value of 
Regionalized Intensive Care for Mechanically Ventilated Medical Patients. Am J Respir Crit Care Med. 2008; 177(3): 285-91. https://doi.org/10.1164/rccm.200708-12140C

[10] Rashid M. Technology and the future of intensive care unit design. Critical Care Nursing Quarterly. 2011; 34(4): 332-60. PMid: 21921718. https://doi.org/10.1097/CNQ.0b013e31822ba7 82

[11] Australasian Health Infrastructure Alliance. Australasian Health Facility Guidelines (AusHFG). In: AusHFG, editor. New South Wales, Australia. 2014.

[12] Roberts D, Clark H, Rock B. Development and implementation of a regional intensive care health service model. Leadership in Health Services. 2013; 26(3): 232-6. https : //doi .org/10.1108/LHS-0 2-2013-0012

[13] Terwiesch C, Diwas K, Kahn J. Working with capacity limitations: operations management in critical care. Critical Care. 2011; 15(4): 308.

[14] Falahinia G, Zareian A, Oshvandi K, et al. Comparison of intensive care units Structural Standards. Iranian Journal of Critical Care Nursing. 2013; 5(4): 222-7.

[15] CICM. Minimum standards for intensivecare units IC-1. Melbourne, Australia.: College of Intensive Care Medicine; 2011. 1-14 p.

[16] Valentin A, Ferdinande P. Recommendations on basic requirements for intensive care units: structural and organizational aspects: ESICM working group on quality improvement. Intensive Care Medicine. 2011; 37(10): 1575-87. https://doi .org/10.1007/s00134-0 11-2300-7

[17] CICM. Minimum standrds for Intensive Care Units seeking accreditation for training in intensive care medicine Australia: College of Intensive Care Medicine of Australia and New Zealand; 2014. 1-7 p

[18] NSW Ministry of Health. NSW Health Guide to the Role Delineation of Clinical Services. Sydney, Australia: NSW Ministry of Health; 2016. 1-127 p.

[19] Lake E. Development of the practice environment scale of the nursing work index. Research in Nursing \& Health. 2002; 25(3): 176-88. https://doi.org/10.1002/nur.10032

[20] Wagner C, Mannion R, Hammer A, et al. The associations between organizational culture, organizational structure and quality management in European hospitals. International Journal for Quality in Health Care. 2014; 26(Supp 1): 74-80. https : //doi .org/10.109 3/intqhc/mzu027

[21] Weled BJ, Adzhigirey LA, Hodgman TM, et al. Critical Care Delivery: The Importance of Process of Care and ICU Structure to Improved Outcomes: An Update From the American College of Critical Care Medicine Task Force on Models of Critical Care. Critical Care Medicine. 2015; 43(7): 1520-5. PMid: 25803647. https://doi.org/10.1097/CCM.0000000000000978

[22] Matlakala M, Bezuidenhout M, Botha A. Challenges encountered by critical care unit managers in the large intensive care units. Curationis. 2014; 37(1): 1-7. PMid: 24832540. https://doi.org/10.4102/ curationis.v37i1.1146

[23] Moneke N, Umeh O. Factors Influencing Critical Care Nurses' Perception of Their Overall Job Satisfaction: An Empirical Study. The Journal of Nursing Administration. 2013; 43(4): 201-7. https: //doi.org/10.1097/NNA.0b013e31828958af

[24] Zayan N, Reizian A, Hamouda G. Relationship between Organizational Climate and Nurse Outcomes. Journal of American Science. 2013; 2(9): 184-92.

[25] Matlakala M, Bezuidenhout M, Botha A. Strategies to address management challenges in larger intensive care units. Journal of Nursing Management. 2014; 23(7): 945-53. https ://doi.org/10.1111/ jonm. 12240
[26] AACN. AACN Standards for Establishing and Sustaining Healthy Work Environments: A Journey to Excellence, 2nd Ed. California: American Association of Critical-Care Nurses; 2016.

[27] Van Bogaert P, Peremans L, Van Heusden D, et al. Predictors of burnout, work engagement and nurse reported job outcomes and quality of care: a mixed method study. BMC Nursing. 2017; 16(1): 1-14. https://doi.org/10.1186/s12912-016-0200-4

[28] Kutney-Lee A, Wu E, Sloane D, et al. Changes in hospital nurse work environments and nurse job outcomes: An analysis of panel data. International Journal of Nursing Studies. 2012; 50(2): 195201. PMid: 22902135. https://doi.org/10.1016/j.ijnurs tu.2012.07.014

[29] Alameddine M, Dainty K, Deber R, et al. The intensive care unit work environment: Current challenges and recommendations for the future. Journal of Critical Care. 2009; 24(2): 243-8. https: //doi.org/10.1016/j.jcrc.2008.03.038

[30] Moss M, Good VS, Gozal D, et al. An Official Critical Care Societies Collaborative Statement: Burnout Syndrome in Critical Care Healthcare Professionals: A Call for Action. Critical Care Medicine. 2016; 44(7): 1414-21. https://doi.org/10.1097/CCM. 000000 0000001885

[31] Hinno S, Partanen P, Vehviläinen J. The professional nursing practice environment and nurse-reported job outcomes in two European countries: a survey of nurses in Finland and the Netherlands. Scandinavian Journal of Caring Sciences. 2012; 26(1): 133-43. https://doi.org/10.1111/j.1471-6712.2011.00920.x

[32] Twigg D, McCullough K. Nurse retention: A review of strategies to create and enhance positive practice environments in clinical settings. International Journal of Nursing Studies. 2014; 51(1): 85-92. https://doi.org/10.1016/j.ijnurstu. 2013.05.015

[33] Van Bogaert P, Kowalski C, Weeks SM, et al. The relationship between nurse practice environment, nurse work characteristics, burnout and job outcome and quality of nursing care: a crosssectional survey. International journal of nursing studies. 2013; 50(12): 1667-77. PMid: 23777786. https://doi.org/10.101 6/j.ijnurstu.2013.05.010

[34] Chowdhury D, Duggal A. Intensive care unit models: Do you want them to be open or closed? A critical review. Neurology India. 2017; 65(1): 39-45. PMid: 28084236.

[35] ANZICS. Centre for Outcome and Resource Evaluation Annual Report 2013-2014. Melbourne: Australian and New Zealand Intensive Care Society Centre for Outcome and Resource Evaluation; 2014.

[36] Aitken L, Burmeister E, Clayton S, et al. The impact of Nursing Rounds on the practice environment and nurse satisfaction in intensive care: Pre-test post-test comparative study. International Journal of Nursing Studies. 2010; 48(8): 918-25. PMid: 21084087. https://doi.org/10.1016/j.ijnurstu.2010.10.004

[37] Gikopoulou D, Tsironi M, Lazakidou A, et al. The Assessment Of Nurses' Work Environment: The Case of a Greek General Hospital. International Journal of Caring Sciences. 2014; 7(1): 269-75.

[38] Bowling A. Research methods in health: investigating health and health services. berkshire: McGraw-Hill Education (UK); 2014.

[39] Maslach C, Jackson S. The measurement of experienced burnout. Journal of Occupational Behaviour. 1981; 2: 99-113. https://doi . org/10.1002/job.4030020205

[40] Abbenbroek B, Duffield C, Elliott D. Selection of an instrument to evaluate the organizational environment of nurses working in intensive care: an integrative review. Journal of Hospital Administration 2014; 3(6): 143-62. https ://doi.org/10.5430/jha.v3n6p143

[41] Duffield C, Roche M, O'Brien-Pallas L, et al. Glueing it Together: Nurses, Their Work Environment and Patient Safety. Sydney, Aus- 
tralia: Centre for Health Services Management, University of Technology, Sydney; 2007.

[42] Simon M, Goes J. Dissertation and Scholarly Research: Recipes for Success. In Dissertation Success. 2012.

[43] Tabachnick B, Fidell L. Using multivariate statistics (6th international edition). California State University - Northridge: Pearson; 2013.

[44] Parker D, Tuckett A, Eley R, et al. Construct validity and reliability of the Practice Environment Scale of the Nursing Work Index for Queensland nurses. International Journal of Nursing Practice. 2010; 16(4): 352-8. https://doi.org/10.1111/j.1440-172X. 2010 $.01851 . \mathrm{x}$

[45] Klopper H, Coetzee S, Pretorius R, et al. Practice environment, job satisfaction and burnout of critical care nurses in South Africa. Journal of Nursing Management. 2012; 20(5): 685-95. https: //doi.org/10.1111/j.1365-2834.2011.01350.x

[46] Pisanti R, Lombardo C, Lucidi F, et al. Psychometric properties of the Maslach Burnout Inventory for Human Services among Italian nurses: a test of alternative models. Journal of Advanced Nursing. 2013; 69(3): 697-707. https://doi.org/10.1111/j.1365-264 8.2012.06114.x

[47] Ganz FD, Toren O. Israeli nurse practice environment characteristics, retention, and job satisfaction. Israel Journal of Health Policy Research. 2014; 3(1): 1.

[48] Bria M, Spânu F, Băban A, et al. Maslach Burnout Inventory-General Survey: Factorial validity and invariance among Romanian healthcare professionals. Burnout Research. 2014; 1(3): 103-11. https: //doi.org/10.1016/j.burn.2014.09.001

[49] Liu J, You L, Zheng J, et al. Effects of Work Environment on Quality of Care in ICUs: A Multisite Survey in China. Journal of Nursing Care Quality. 2016; 31(3): E1-E8. PMid: 26796973. https://doi.org/10.1097/NCQ.0000000000000160

[50] Field A. Discovering statistics using IBM SPSS statistics: Sage; 2013.

[51] AIHW. Nursing and midwifery workforce 2014. Canberra: AIHW; 2014.

[52] Cohen J. Statistical power analysis for the behavioral sciences. 2nd ed. New York: Academic Press; 2013. 440 p.

[53] Coetzee S, Klopper H, Ellis S, et al. A tale of two systems-Nurses practice environment, well being, perceived quality of care and patient safety in private and public hospitals in South Africa: A questionnaire survey. International Journal of Nursing Studies. 2013; 50(2): 162-73. PMid: 23218020. https://doi.org/10.1016/j. ijnurstu.2012.11.002

[54] Roche M, Laschinger H, Spence K, et al. Testing the Nursing Worklife Model in Canada and Australia: A multi-group comparison study. International journal of nursing studies. 2015; 52(2): 52534. PMid: 25468280. https://doi.org/10.1016/j.ijnurstu .2014 .10 .016

[55] Brewer CS, Kovner CT, Djukic M, et al. Impact of transformational leadership on nurse work outcomes. Journal of Advanced Nursing. 2016; 72(11): 2879-2893. PMid: 27346330. https://doi.org/10 $.1111 / j$ an. 13055

[56] Ulrich BT, Lavandero R, Woods D, et al. Critical Care Nurse Work Environments 2013: A Status Report. Critical Care Nurse. 2014; 34(4): 64-79. https://doi .org/10.4037/ccn2014731

[57] Weigl M, Stab N, Herms I, et al. The associations of supervisor support and work overload with burnout and depression: a crosssectional study in two nursing settings. Journal of Advanced Nursing. 2016; 72(8): 1774-88. https://doi.org/10.1111/jan.12948

[58] dos Santos Alves DF, da Silva D, et al. Nursing practice environment, job outcomes and safety climate: a structural equation mod- elling analysis. Journal of Nursing Management. 2016; 25(1): 46-55 https://doi.org/10.1111/jonm.12427

[59] Duffield C, Frew B, Dimitrelis S, et al. Leadership skills for nursing unit managers to decrease intention to leave. Nursing: Research and Reviews. 2015; 5: 57-64.https://doi.org/10.2147/nrr.s461 55

[60] Stanley D. Clinical leadership characteristics confirmed. Journal of Research in Nursing. 2014; 19(2): 118-28. https ://doi.org/10 $.1177 / 1744987112464630$

[61] Welp A, Meier L, Manser T. The interplay between teamwork, clinicians' emotional exhaustion, and clinician-rated patient safety: a longitudinal study. Critical Care. 2016; 20(1): 1-10. https: //doi.org/10.1186/s13054-016-1282-9

[62] Steege LM, Rainbow JG. Fatigue in hospital nurses - 'Supernurse' culture is a barrier to addressing problems: A qualitative interview study. International Journal of Nursing Studies. 2017; 67: 20-8. https://doi.org/10.1016/j.ijnurstu.2016.11.014

[63] Dawson AJ, Stasa H, Roche MA, et al. Nursing churn and turnover in Australian hospitals: nurses perceptions and suggestions for supportive strategies. BMC Nursing. 2014; 13(1): 1-10. https : //doi.org/10.1186/1472-6955-13-11

[64] WFCCN. Declaration of Buenos Aires: position statement on the provision of critical care nursing workforce. Buenis Aires, Argentina: World Federation of Critical Care Nurses; 2005.

[65] Haerkens M, Kox M, Lemson J, et al. Crew Resource Management in the Intensive Care Unit: a prospective 3-year cohort study. Acta Anaesthesiologica Scandinavica. 2015; 59(10): 1319-29. PMid: 26079640. https://doi.org/10.1111/aas.12573

[66] Djukic M, Kovner C, Brewer C, et al. Work environment factors other than staffing associated with nurses' ratings of patient care quality. Journal of Nursing Administration. 2012; 42(10): S17-S26. PMid: 22976890.

[67] Moss M, Good VS, Gozal D, et al. A Critical Care Societies Collaborative Statement: Burnout Syndrome in Critical Care Healthcare Professionals. A Call for Action. American Journal of Respiratory and Critical Care Medicine. 2016; 194(1): 106-13. https: //doi.org/10.1164/rccm.201604-0708ST

[68] Vahey D, Aiken L, Sloane D, et al. Nurse burnout and patient satisfaction. Medical Care. 2004; 42(2): 57-66. https ://doi.org/10 $.1097 / 01 . \mathrm{mlr} .0000109126 .50398 .5 \mathrm{a}$

[69] Li L, Ruan H, Yuan W. The Relationship between Social Support and Burnout among ICU Nurses in Shanghai: a Cross-Sectional Study. Chinese Nursing Research. 2015; 2(3): 45-50. https ://doi.org/ $10.1016 /$ j.cnre. 2015.04 .003

[70] Samur M, Intepeler S. Factors Influencing Nurses' Perceptions of Occupational Safety. Archives of Environmental \& Occupational Health. 2016; 72(1): 45-52. https://doi.org/10.1080/193382 44.2016.1156045

[71] Mealer M. Burnout Syndrome in the Intensive Care Unit. Future Directions for Research. Annals of the American Thoracic Society. 2016; 13(7): 997-8. https ://doi .org/10.1513/AnnalsATS 20 1604-280ED

[72] Regan S, Laschinger HK, Wong CA. The influence of empowerment, authentic leadership, and professional practice environments on nurses' perceived interprofessional collaboration. Journal of nursing management. 2016; 24(1): E54-E61. PMid: 25703584 https://doi.org/10.1111/jonm. 12288

[73] Matlakala M. The views of intensive care nurses regarding shortterm deployment: original research. Curationis. 2015; 38(1): 1-5. https://doi.org/10.4102/curationis.v38i1.1478 
[74] Iapichino G, Radrizzani D, Rossi C, et al. Proposal of a flexible structural-organizing model for the Intensive Care Units. Minerva anestesiologica. 2007; 73(10): 501-6. PMid: 17912203.

[75] Cho E, Sloane DM, Kim E-Y, et al. Effects of nurse staffing, work environments, and education on patient mortality: An observational study. International Journal of Nursing Studies. 2014; 52(2): 535-42. https://doi.org/10.1016/j.ijnurstu. 2014.08.006

[76] Dall'Ora C, Griffiths P, Ball J, et al. Association of $12 \mathrm{~h}$ shifts and nurses' job satisfaction, burnout and intention to leave: findings from a cross-sectional study of 12 European countries. BMJ Open. 2015; 5(9): e008331. https://doi.org/10.1136/bmjopen-2 015-008331

[77] Kunaviktikul W, Wichaikhum O, Nantsupawat A, et al. Nurses' extended work hours: patient, nurse and organizational outcomes. International nursing review. 2015; 62(3): 386-93. PMid: 25997841. https://doi.org/10.1111/inr.12195

[78] Moreno Arroyo MC, Jerez González JA, Cabrera JS, et al. Seven hour shifts versus 12 hours in intensive nursing care: going against the tide. Enfermeria Intensiva. 2013; 24(3): 98-103. https://doi org/10.1016/j.enfi.2013.04.002

[79] Pryce C. Impact of shift work on critical care nurses. Canadian Journal of Critical Care Nursing. 2016; 27(4): 17-21.

[80] Pastores SM. Staffing Ratios and Workload in Critically Ill Patients: Do They Impact Outcomes? Critical Care Medicine. 2015; 43(8): 1775-6. PMid: 26181116. https://doi.org/10.1097/CCM.00 00000000001040

[81] Lobo VM, Ploeg J, Fisher A, et al. Critical Care Nurses' Perceptions of the Outcomes of Working Overtime in Canada. Nursing Outlook. 2017; In press. Epub 7 Jan 2017. https://doi.org/10.1016/j. outlook.2016.12.009

[82] Griffiths P, Dall'Ora C, Simon M, et al. Nurses' Shift Length and Overtime Working in 12 European Countries: The Association With Perceived Quality of Care and Patient Safety. Medical Care. 2014; 52(11): 975-81. https://doi.org/10.1097/MLR.0000000000 000233

[83] Liu LF, Lee S, Chia PF, et al. Exploring the Association Between Nurse Workload and Nurse-Sensitive Patient Safety Outcome Indi- cators. Journal of Nursing Research. 2012; 20(4): 300-9. https: //doi.org/10.1097/jnr.0b013e3182736363

[84] Van Bogaert P, Peremans L, Diltour N, et al. Staff Nurses' Perceptions and Experiences about Structural Empowerment: A Qualitative Phenomenological Study. PloS One. 2016; 11(4): e0152654. PMid: 27035457. https://doi.org/10.1371/journal.pone .0152654

[85] Georgiou E, Papathanassoglou E, Pavlakis A. Nurse-physician collaboration and associations with perceived autonomy in Cypriot critical care nurses. Nursing in Critical Care. 2015; 22(1): 29-32. https://doi.org/10.1111/nicc.12126

[86] Lake E. The Nursing Practice Environment. Medical Care Research and Review. 2007; 64(2 suppl): 104S-22S. https ://doi.org/10 $.1177 / 1077558707299253$

[87] Maslach C, Jackson S, Leiter M. Maslach Burnout Inventory: Manual. Palo Alto, CA: Consulting Psychologist Press; 1996.

[88] de Paiva Fonseca TC, Mello R. Burnout syndrome among nursing professionals of intensive units in a public hospital. Journal of Nursing Administration. 2015; 10(1): 296-303.

[89] Chuang CH, Tseng PC, Lin CY, et al. Burnout in the intensive care unit professionals: A systematic review. Medicine. 2016; 95(50): e5629. https://doi.org/10.1097/MD.0000000000005629

[90] Roche M, Duffield C, Friedman S, et al. Changes to nurses' practice environment over time. Journal of Nursing Management. 2016; 24(5): 666-75. https://doi .org/10.1111/jonm. 12371

[91] Galletta M, Portoghese I, D’Aloja E, et al. Relationship between job burnout, psychosocial factors and health care-associated infections in critical care units. Intensive and Critical Care Nursing. 2016; 34: 59-66. https ://doi.org/10.1016/j.iccn.2015.11.004

[92] Trout AT, Kaufmann TJ, Kallmes DF. No Significant Difference ... Says Who? American Journal of Neuroradiology. 2007; 28(2): 195-7. PMid: 17296976.

[93] Guyatt GH, Oxman AD, Kunz R, et al. GRADE guidelines 6. Rating the quality of evidence-imprecision. Journal of clinical epidemiology. 2011; 64(12): 1283-93. PMid: 21839614. https : //doi.org/10.1016/j.jclinepi.2011.01.012 